\title{
Política além da vida: o romance espírita Nosso Lar e a ideia de organização política e social na vida após a morte
}

Alexsandro Melo Medeiros ${ }^{1}$

Resumo: A literatura espírita compreende uns cem números de obras de divulgação doutrinária dentre as quais se destacam os romances, as crônicas, os poemas e cuja autoria é atribuída aos mortos. O que vemos nestas obras? Em geral a mensagem espírita é clara: a vida não cessa. A morte nada mais é do que uma passagem, para uma outra realidade, uma outra dimensão. O que acontece então no pós morte? O público leitor de romances espíritas encontra uma série de questões ligadas à cosmologia própria do espiritismo que enfatiza a realidade da vida após a morte, a reencarnação, a lei moral de causa e efeito/evolução e muitos outros temas. Neste artigo pretende-se dar uma resposta a esta questão do ponto de vista de como se organiza a vida em sociedade no chamado plano espiritual, tomando como base um dos mais conhecidos romances da literatura espírita, que se transformou inclusive em uma produção cinematográfica, a saber, Nosso Lar ditado pelo espírito André Luiz através da psicografia de Chico Xavier. Como metodologia utilizou-se a pesquisa bibliográfica tomando como fonte principal a obra Nosso Lar, além de artigos, teses, dissertações e livros que discorrem sobre o tema em análise. Conclui-se que Nosso Lar, ao longo de sua narrativa, nos apresenta uma forma de organização política e social em parte muito semelhantes ao do plano terreno, com governadoria, ministérios, organização de trabalho, serviços de comunicação, transporte e que comporta uma estrutura política hierárquica de caráter eminentemente moral, evolutivo e espiritual.

Palavras-chave: Organização Social. Literatura Espírita. Plano espiritual.

Abstract: The Spiritist literature comprises a hundred works of doctrinal dissemination, among which the novels, the chronicles, the poems whose the authorship are attributed to the dead. What do we see in these works? In general, the spiritist message is clear: life does not cease. Death is nothing more than a passage, to another reality, another dimension. What happens after death? The readers of Spiritist novels find a series of questions related to the cosmology of Spiritism that emphasizes the reality of life after death, reincarnation, moral law of cause and effect / evolution, and many other subjects. This article intends to give an answer to this question from the point of view of how one organizes the life in society in the called spiritual plane, taking as base one of the most well-known novels of the spiritist literature, that has turned into a cinematographic production: Nosso Lar (the english version of the International Spiritist Council, of 2011, retained the title of the work Nosso Lar, with the subtitle: Life in the Spirit World) dictated by the spirit André Luiz through the psychography of Chico Xavier. As a methodology, the bibliographical research was based on the work Nosso Lar, as well as articles, theses, dissertations and books about it. It is concluded that Nosso Lar, throughout its narrative, presents us with a form of political and social organization in part very similar to the one of the terrestrial plane, with government, ministries, work

\footnotetext{
${ }^{1}$ Doutorando do Programa de Pós-Graduação em Sociedade e Cultura da Amazônia/UFAM. Professor Adjunto da Universidade Federal do Amazonas. Bolsista e Pesquisador Fundação de Amparo à Pesquisa no Estado do Amazonas. E-mail: alexsandromedeiros@ufam.edu.br
} 
organization, communication services, transport and that it has a structure hierarchical politics of an eminently moral, evolutionary and spiritual character.

Keywords: Social Organization. Spiritist Literature. Spiritual plane.

\section{Introdução}

A literatura espírita, que movimenta um universo de milhões de leitores a partir de suas publicações (LEWGOY, 1998), tem grande popularidade no Brasil, e foi objeto de análise de Sandra Stoll em Espiritismo à brasileira (2003). A mesma pesquisadora, então professora do departamento de Antropologia da Universidade Federal do Paraná (UFPR), destaca uma reportagem da revista Época de maio de 2003 que ressalta o crescimento da literatura espírita como um fenômeno editorial no Brasil: "Tradicionalmente vendidos nos redutos kardecistas, os livros psicografados - escritos por pessoas que se dizem conectadas com almas que enviam mensagens do Além - (vêm despertando) a atenção das grandes editoras" (STOLL, 2004, p. 181). O que é corroborado por Lewgoy (1998, p. 95-96):

Por exemplo, o livro "Violetas na Janela", psicografado por Vera Lúcia Marinzeck de Carvalho (1993) alcançou a cifra de duzentos e setenta e cinco mil exemplares vendidos nos anos de 1994 e 1995, extraordinária se considerarmos que o Brasil é tido como um país em que se lê muito pouco e em que as tiragens das editoras atingem, em geral, cerca de poucos milhares de exemplares. Aos cinquenta anos desde sua primeira edição, em 1944, foi lançada uma edição comemorativa de um milhão de exemplares do livro "Nosso Lar", psicografado por Chico Xavier, este sem sombra de dúvida o principal escritor mediúnico de nosso país, responsável pela psicografia de quase quatrocentos livros. Da mesma forma os livros assinados por Divaldo Franco, Zíbia Gasparetto e Ivone Pereira constam em qualquer livraria espírita do país, atestando a popularidade deste gênero de literatura.

Stoll (2009, p. 155) destaca ainda que "A literatura espírita compreende um cem número de obras de divulgação doutrinária (romances, crônicas, poemas e outros), cuja autoria é atribuída aos 'mortos"'.

O que vemos nestas obras? Em geral a mensagem espírita é clara: a vida não cessa. A morte nada mais é do que uma passagem, para uma outra realidade, uma outra dimensão. E no caso de um grande número dos romances mediúnicos espíritas, como os psicografados por Zilda Gama², Vera Lúcia Marinzeck, Chico Xavier, Zíbia Gasparetto, Robson Pinheiro e tantos outros ressaltam precisamente essa realidade da vida após a morte, e é sobre essa realidade que o público leitor busca referências:

O público leitor de romances espíritas busca a continuidade literária de um tipo de experiência ligada à cosmologia própria do kardecismo, que enfatiza a realidade da vida após a morte, a reencarnação e a lei moral de causa e efeito/evolução (LEWGOY, 1998, p. 106).

O que acontece então no pós morte? O objetivo deste artigo consiste em dar uma resposta a esta pergunta tão somente do ponto de vista de como se organiza a vida em

\footnotetext{
2 De acordo com Prata (2016, p. 126), Zilda Gama (1878-1959) - mineira de Juiz de Fora -, é considerada a primeira médium, no Brasil, a inaugurar um novo ciclo na literatura mediúnica e foi em 1916 que psicografou seu primeiro romance, intitulado Na Sombra e na Luz, de autoria espiritual de ninguém menos do que Victor Hugo: "a FEB [Federação Espírita Brasileira] publicou de 1916 a 1946, sob a tutela do mesmo espírito Victor Hugo, os romances Do Calvário ao Infinito (1922), Redenção (1929), Dor Suprema (1939) e Almas Crucificadas (1946)".
} 
sociedade no chamado plano espiritual, de acordo com os ensinamentos que nos são transmitidos através da literatura espírita e, de modo mais específico, com base no romance Nosso Lar ditado pelo espírito André Luiz através da psicografia de Chico Xavier.

A obra apresenta o drama existencial do personagem principal André Luiz após a sua morte que, para espanto do personagem, percebe que a morte não é o fim de tudo. André Luiz narra suas impressões, a confusão que tomava conta de seu ser: "'personagem-narrador', descreve seus sentimentos e percepções em sua presente condição. O personagem percebe que seu corpo havia falecido, mas incrivelmente em algum lugar, ainda desconhecido, a sua vida continuava" (ELIAS, 2013, p. 1).

Como metodologia utilizou-se a pesquisa bibliográfica tomando como fonte principal a obra Nosso Lar, além de artigos, teses, dissertações e livros que discorrem sobre o tema em análise. A pesquisa bibliográfica utiliza como base as teorias já publicadas em livros, artigos científicos, dissertações de mestrado, teses de doutorado. "Na pesquisa bibliográfica o investigador irá levantar o conhecimento disponível na área, identificando as teorias produzidas, analisando-as e avaliando sua contribuição para auxiliar a compreender ou explicar o problema objeto da investigação" (KÖCHE, 2015, p. 122). A pesquisa bibliográfica ajuda a ampliar o conhecimento sobre um determinado objeto de pesquisa, a ter um maior domínio e conhecimento sobre o assunto, descrever o estado da arte, daquele momento, do tema em questão.

\section{A Obra Nosso Lar}

Nosso Lar faz parte de uma série literária psicografada pelo médium mineiro Francisco de Paula Cândido Xavier, mais conhecido como Chico Xavier. O conjunto de livros da série A Vida no Mundo Espiritual, da autoria espiritual de André Luiz ${ }^{3}$, teve início com a obra Nosso Lar, lançado no segundo semestre de 1944 e teve fim com a edição do livro E a vida continua..., em 19684. "Maior clássico do espiritismo brasileiro, o romance Nosso lar, de 1943, é de longe o livro mais vendido e divulgado da extensa obra mediúnica de Chico Xavier" (LEWGOY, 2001, p. 60). Em 2010, foi produzido o filme de mesmo nome, dirigido por Wagner Assis, "através de uma coprodução entre a Globo Filmes e Cinética Filmes, que recebeu o apoio da Federação Espírita Brasileira (FEB) e da Funcine" (VIDAL, 2014, p. 38; ASSIS, 2010). O filme, como o livro, desperta no telespectador a curiosidade sobre a realidade pós morte: "Como será do lado de lá? O que encontraremos? Será que existirá mesmo outra vida? São muitas as perguntas. E justamente por tratar de um tema tão instigante que o filme exigiu um grande investimento" (PRATA, 2016, p. 230)5.

A obra Nosso Lar "foi a primeira sociedade urbana do plano espiritual a ser retratada em detalhes" (BERENGUEL, 2010, p. 77) através da mediunidade de Francisco Cândido

\footnotetext{
${ }^{3}$ Utilizando a nomenclatura de Gonçalves (2011, p. 97) ao analisar a produção discursiva psicográfica espírita teríamos: André Luiz como o sujeito-autor-espiritual; e Chico Xavier como o sujeito-autor-psicógrafo.

${ }^{4}$ A série é composta pelas seguintes obras: Nosso Lar (1944), Os Mensageiros (1944), Missionários da Luz (1945), Obreiros da Vida Eterna (1946), No Mundo Maior (1947), Libertação (1949), Entre a Terra e o Céu (1954), Nos Dominios da Mediunidade (1955), Ação e Reação (1957), Evolução em Dois Mundos (1958), Mecanismos da Mediunidade (1960), Sexo e destino (1963), E a vida continua... (1968). Ao todo são 13 livros, escritos "em forma de prosa, mais especificamente, em forma de romance" (SOARES, 2012, p. 132) sendo que "os quatro últimos números, foram concebidos a partir da parceria dos médiuns Chico Xavier e Waldo Vieira” (id., ibidem, p. 132).

5 Para as críticas, controvérsias e impressões que o lançamento do filme causou, ver: Prata (2016, p. 229-239) e Vidal (2014, p. 38-41).
} 
Xavier e também por Heigorina Cunha ${ }^{6}$. Nosso Lar é apenas uma, das muitas colônias existentes no plano espiritual, dedicadas ao trabalho e ao socorro espiritual, cada uma com traços peculiares tal como sucede no plano terreno. Tal como ocorre com as cidades terrenas que não são idênticas entre si, assim também acontece com as colônias espirituais.

O nome do autor espiritual da obra, André Luiz - “o 'repórter do além', como ficou conhecido" (PRATA, 2016, p. 191) -, "é um nome fictício, usado para que não pudesse ser identificado. $\mathrm{O}$ anonimato se deu por conta de ainda possuir parentes encarnados, ou seja, em respeito a eles" (BERENGUEL, 2010, p. 56). E também para evitar algum malestar em relação a direitos autorais pois, em 1944, ocorreu o caso Humberto de Campos "quando a viúva do renomado escritor, em conjunto com os filhos do casal, deram entrada na Justiça com uma ação declaratória contra a Federação Espírita Brasileira (FEB) e o médium Francisco Cândido Xavier" (VIDAL, 2014, p. 27). A querela envolvia as obras psicografadas por Chico Xavier e assinadas por Humberto de Campos.

A defesa de Chico foi bancada pela Federação Espírita Brasileira (que resultou posteriormente no clássico espírita A psicografia perante os tribunais, do advogado Miguel Timponi). O juiz decidiu que os direitos autorais referiam-se à obra reconhecida em vida do autor, não havendo condição do tribunal se pronunciar sobre a existência ou não da mediunidade. No entanto, o nome Humberto de Campos é substituído pelo pseudônimo “irmão X” (LEWGOY, 2001, p. 60)7.

A obra Nosso Lar, como destaca Stoll (2003, p. 105), tem como principal objetivo "apresentar ao mundo a realidade do além-túmulo".

[...] o livro relata a experiência pós-morte do autor espiritual na colônia "Nosso Lar", situada acima da Terra. O protagonista narra sua experiência nessa localidade, reiterando as crenças e valores espíritas sobre a substância do cotidiano numa esfera espiritual, e sobre a evolução através do aprendizado, da caridade e do trabalho. O texto é formado por uma série de capítulos curtos, com o predomínio de extensos diálogos doutrinários sobre os valores espíritas, apresentando uma forma imaginada de organização social num mundo governado burocraticamente por ministérios, onde os habitantes se dedicam a tarefas edificantes, atualizando uma espécie de utopia espírita de vida comunitária (LEWGOY, 1998, p. 107).

A obra corresponde a uma espécie de autobiografia do sujeito-autor-espiritual André Luiz que "relata sua vivência como sujeito-espírito desencarnado, na colônia Nosso Lar [...] Recém-chegado ao mundo espiritual, o sujeito-autobiógrafo traduz com riqueza de detalhes as suas percepções sobre a colônia” (GONÇALVES, 2011, p. 98).

Dentre os inúmeros aspectos abordados na obra, a partir do relato do resgate de André Luiz da região denominada de Umbral ${ }^{8}$ por trabalhadores da colônia Nosso Lar (nos primeiros capítulos), Vidal (2014, p. 25) destaca "a descrição da vida cotidiana da colônia. André

\footnotetext{
${ }^{6}$ Heigorina Cunha, médium da cidade mineira de Sacramento, foi a responsável pelos desenhos que procuram retratar aspectos da colônia espiritual Nosso Lar, bem como de um Plano Piloto que corresponderia a uma espécie de planta baixa da cidade. Tais desenhos também foram obtidos via mediúnica, sob a orientação do espírito Lucius (CUNHA; XAVIER, 1999). Na obra onde é possível visualizar os desenhos, a médium Heigorina Cunha chama a atenção do leitor para o fato de que não era desenhista e que, por isso, não dispunha da precisão técnica para retratar com fidelidade os aspectos que pôde contemplar da cidade. Em 1994 a médium Heigorina Cunha publicou um segundo livro retratando desenhos de cidades espirituais, como a Colônia Espiritual de Eurípedes Barsanulfo (CUNHA, 2009), localizada na região da cidade mineira de Sacramento.

7 Para detalhes do caso ver: Rocha (2008) e Prata (2016, p. 167-172).

8 Uma espécie de zona purgatorial (GONÇALVEZ, 2011, p. 99).
} 
Luiz passa a conhecer suas particularidades" e absorver novos conhecimento relativos ao Umbral e outras colônias espirituais (sobretudo entre os capítulos oitavo ao décimo segundo); André Luiz também recebe "orientações sobre as atividades que poderá empreender em Nosso Lar [...] [e iniciar] seus trabalhos nas 'câmaras de retificação' como auxiliar de limpeza” (id., ibidem, p. 25-26 - capítulos vinte a vinte e três da obra). Já entre os capítulos quarenta e um até o quarenta e cinco a Segunda Grande Guerra aparece como pano de fundo e serve para abordagens de conceitos como trevas e esperança.

\section{A Colônia Nosso Lar}

Através de Lísias ${ }^{9}$ ficamos sabendo que a cidade espiritual foi fundada por portugueses, desencarnados no Brasil no século XVI. A cidade está localizada acima da cidade terrena do Rio de Janeiro e "[...] carece de medidas que nos propiciem uma exata compreensão do seu tamanho. Mas, poderemos imaginar sua magnitude pelas referências que André Luiz nos faz. É uma cidade, amplamente disposta, para um milhão de habitantes" (CUNHA; XAVIER, 1999, p. 21). A colônia Nosso Lar é apresentada por Lísias

como um lugar construído com o objetivo de propiciar aos desencarnados a oportunidade de trabalho e aprendizado entre as experiências reencarnatórias. Configura-se, portanto, como uma zona de transição onde os sujeitos-Espíritos permanecem o tempo necessário para adquirirem o direito de ascender para uma esfera de habitação espiritual mais elevada ou de reencarnarem na Terra. $\mathrm{O}$ trabalho na colônia está, portanto, organizado de forma a atender a diversidade de necessidades dos Espíritos (GONÇALVES, 2011, p. 116).

André Luiz descreve Nosso Lar com grandes construções, edifícios, extensos jardins, animais, vastas avenidas, ar puro, sem qualquer sinal de inércia ou ociosidade, com festividades públicas, banhada pelas águas do Rio Azul, com uma população de mais de um milhão de habitantes e uma cópia melhorada da Terra:

Cores mais harmônicas, substâncias mais delicadas. Forrava-se o solo de vegetação. Grandes árvores, pomares fartos, jardins deliciosos. Desenhavam-se montes coroados de luz, em continuidade à planície onde a colônia repousava. Todos os departamentos apareciam cultivados com esmero. A pequena distância, alteavam-se graciosos edifícios. Alinhavam-se a espaços regulares, exibindo formas diversas. Nenhum sem flores à entrada, destacando-se algumas casinhas encantadoras, cercadas por muros de hera, onde rosas diferentes desabrochavam, aqui e ali, adornando o verde de cambiantes variados (XAVIER, 1944, p. 45-46).

Berenguel (2010, p. 85-86) destaca a importância da água para a colônia: "um elemento de grande importância [...] ela é empregada como alimento e remédio [...] o Bosque das Águas, é o grande reservatório que serve todas as atividades da Colônia".

No marco zero da colônia está o palácio da Governadoria, um palácio de grande beleza e torres altíssimas, para onde convergem os seis ministérios. "Todos começam na

\footnotetext{
${ }^{9}$ Lísias é um funcionário da colônia “designado pelo médico espiritual [Henrique de Luna] para prestar-lhe [à André Luiz] assistência diária” (GONÇALVES, 2011, p. 115). É pelo diálogo constante com Lísias que André Luiz adquire novos saberes relativos à colônia e ao plano espiritual de modo geral. Lísias é designado como visitador dos serviços de saúde (XAVIER, 1944, p. 36), uma espécie de enfermeiro no plano espiritual. Lísias coopera nos serviços de enfermagem e cuida das "necessidades de socorros, ou providências que se refiram a enfermos recém-chegados" (GONÇALVES, 2011, p. 115). De acordo com Lísias, existem numerosos servidores do gênero em Nosso Lar.
} 
Governadoria, estendendo-se em forma triangular" (XAVIER, 1944, p 53), onde reside o Governador que tem para si a colaboração de três mil funcionários. A Governadoria fica no centro da cidade que tem a forma de uma estrela de seis pontas: "a cidade está dividida em seis módulos, cada um deles partindo da Governadoria, junto à qual se eleva à torre de cada Ministério, configurando-se como o centro administrativo" (CUNHA; XAVIER, 1999, p. 20).

A Colônia conta também com recintos de conferências, chamados de "salões verdes", onde os Ministros, o próprio Governador e estudiosos em geral ministram seus ensinamentos. Estes salões estão espalhados pela colônia e localizam-se no Bosque das Águas (Ministério da União Divina), nos parques de Educação (Ministério do Esclarecimento), há ainda o recinto destinado às palestras do Governador e o salão da Ministra Veneranda. "Próximo ao Ministério da Regeneração e ao Ministério do Auxílio encontra-se o Parque Hospitalar. Ao lado do Ministério da União Divina, o Bosque das Águas, Bem próximo ao Ministério da Elevação, vê-se o Campo da Música” (BERENGUEL, 2010, p. 89).

O capítulo 37 é destinado a "preleção da ministra" Veneranda e assim André Luiz descreve o local da preleção, como um "grande salão em plena natureza. Verdadeira maravilha o recinto verde, onde grandes bancos de relva nos acolheram confortadoramente" (XAVIER, 1944, p. 201).

\section{Governadoria e Ministérios}

Nosso Lar conta com um Governador Espiritual e cerca de setenta e dois colaboradores do Governador, também chamados de ministros, dos quais Clarêncio (o responsável pelo resgate de André Luiz das zonas inferiores, chamada Umbral) é um deles.

Eis o que ficamos sabendo a respeito do Governador: realiza preces diárias que são ouvidas por todos os membros da Colônia; é o principal responsável pela administração da Colônia e para isso faz visitas periódicas aos ministérios; é "o trabalhador mais infatigável e mais fiel que todos nós reunidos" (XAVIER, 1944, p. 53); é o que menos tem tempo para realizar viagens em outras esferas e participar dos entretenimentos habituais ou festividades públicas; tem alegria em servir e "sua assistência carinhosa a tudo e a todos atinge" (XAVIER, 1944, p. 53); está no cargo há 114 anos; realiza palestras e conversações com os membros da Colônia, com os trabalhadores, os ministros, os enfermos; realiza aos domingos culto evangélico no Ministério da Regeneração; sua fisionomia revela, "ao mesmo tempo, a sabedoria do velho e a energia do moço; a ternura do santo e a serenidade do administrador consciencioso e justo. Alto, magro, envergando uma túnica muito alva, olhos penetrantes e maravilhosamente lúcidos” (XAVIER, 1944, p. 233).

A ocupação de cargos como o de governador da colônia e dos Ministros são ocupados por sujeitos-Espíritos com um grau de evolução moral muito elevada, isto explica o fato de, no mundo espiritual, esses cargos serem ocupados pelo mesmo Espírito durante muitos anos como é o caso do Governador da colônia (GONÇALVES, 2011, p. 117).

É Lísias quem explica a André Luiz como se divide a colônia de Nosso Lar, com seis ministérios, cada um com doze Ministros. São eles: o Ministério da Regeneração, do Auxílio, da Comunicação, do Esclarecimento, da Elevação e da União Divina.

Os quatro primeiros nos aproximam das esferas terrestres, os dois últimos nos ligam ao plano superior, visto que a nossa cidade espiritual é zona de transição. Os serviços mais grosseiros

https://periodicos.unifap.br/index.php/letras

Macapá, v. 8, n. 3, $2^{\circ}$ sem., 2018 
localizam-se no Ministério da Regeneração, os mais sublimes no da União Divina. Clarêncio, nosso chefe e amigo, é um dos ministros do Auxílio (XAVIER, 1944, p. 51).

No Ministério do Esclarecimento constam os arquivos de fundação da Colônia. Além disso o Ministério possui uma "Seção do Arquivo" onde ficam registrados os fatos particulares de cada indivíduo, uma espécie de memória onde estão registrados fatos atinentes a todas as vidas pregressas. Esses fatos também ficam registrados no espírito, mas para ter acesso a essa memória é necessário preparo e evolução. Quando o espírito não está pronto para ter esse acesso, é possível submeter-se a determinadas operações psíquicas com magnetizadores espirituais que facilitam a operação e "aplicam passes [movimentos com as mãos] no cérebro, despertando certas energias adormecidas [...] a fim de penetrar os domínios emocionais das recordações" (XAVIER, 1944, p. 118).

O Ministério da Regeneração é responsável por receber os "recém-chegados da zona do Umbral" que são instalados "nas Câmaras de Retificação pertencentes a esse Ministério" (PRATA, 2016, p. 197).

O Ministério da Comunicação é o responsável pelos serviços de comunicação prestados na colônia, tanto de comunicação com outras colônias quanto os serviços de comunicação daqueles que desejam entram em contato com os parentes que ainda vivem no plano terreno.

Nosso Lar apresenta o Ministério da Comunicação, portanto, como o órgão que atua na colônia como sendo o responsável sobre o controle da produção e da circulação dos discursos entre desencarnados de esferas diferentes e entre desencarnados e encarnados terrestres (GONÇALVES, 2011, p. 134).

A grande função do Ministério do Auxílio é o de planejar novas reencarnações e, de todos, o Ministério da União Divina é o mais elevado "pois ele estava atrelado às esferas da mais alta evolução espiritual” (PRATA, 2016, p. 197).

\section{Trabalho na Colônia Espiritual}

Não existe ociosidade na colônia. Há trabalhos de todo gênero. O trabalho é recompensado com uma espécie de salário, chamado de bônus-hora - uma espécie de unidade monetária padrão -, que corresponde aos pontos relativos a cada hora de serviço e é possível ganhar até 72 bônus-hora por semana mas essa remuneração pode ser duplicada ou triplicada de acordo com o trabalho realizado. "Cada trabalhador recebe o bônus-hora do Ministério a que prestou serviço [...] no Ministério da Regeneração temos o bônus-hora regeneração [...] e assim sucessivamente" (BERENGUEL, 2010, p. 87).

A Colônia possui um Serviço de Assistência Médica (XAVIER, 1944, p. 32), que fica localizada no Ministério do Auxílio (XAVIER, 1944, p. 50). O Ministério do Auxílio é o local "onde se faz o atendimento aos doentes, preparam-se reencarnações terrenas, são formados grupos de socorro aos habitantes do Umbral (zona de sofrimento)" (BERENGUEL, 2010, p. 83). Vale lembrar que o próprio André Luiz foi resgatado do Umbral, por Clarêncio e mais dois companheiros e conduzido a colônia que dá título ao livro.

Há também as Câmaras de Retificação no Ministério da Regeneração, para onde são levados os espíritos resgatados do Umbral. "As Câmaras de Retificação se comunicam com as equipes de Samaritanos e socorristas através de um pequeno aparelho em forma de contato elétrico. Sempre que espíritos são resgatados, o auxílio para o recolhimento é 
solicitado" (BERENGUEL, 2010, p. 92). As equipes de Samaritanos correspondem a uma organização de Espíritos benfeitores (XAVIER, 1944, p. 147).

A colônia também conta com uma oficina do Serviço de Trânsito e Transporte e um meio de transporte, chamado de aeróbus: um carro grande, suspenso ao solo mais de 5 metros, que se move a grande velocidade.

$\mathrm{Na}$ colônia espiritual existe relações coletivas mas também existe a propriedade particular. As grandes construções são patrimônios comuns sob o controle da Governadoria. Mas com o dinheiro existente na colônia espiritual (o bônus-hora, que funciona como valor aquisitivo mas que não é propriamente uma moeda, mas uma ficha de serviço individual), que não deixa de ser um tipo de propriedade, é possível comprar uma moradia (nunca mais do que uma), em média por trinta mil bônus-hora.

A questão da moradia é destaque no romance. Um núcleo de trabalhadores que assistem as zonas inferiores residem em casas que possuem postos de alerta, com emissoras radiotelevisoras apropriadas. Foi de uma dessas residências que André Luiz viu e ouviu o locutor da Emissora do Posto Dois, irradiando um apelo pela paz na Terra, por ocasião da última Grande Guerra (PRATA, 2016, p. 198) ${ }^{10}$.

É comum ocorrer também a produção de vestuário e alimentação (há fábricas de preparação de suco, tecidos e artefatos em geral que dão emprego a mais de cem mil espíritos). Com o trabalho, é possível adquirir certos direitos, dentre eles o direito a uma moradia. "Cada habitante de "Nosso Lar" recebe provisões de pão e roupa, no que se refere ao estritamente necessário; mas os que se esforçam na obtenção de bônus-hora conseguem certas prerrogativas na comunidade social" (XAVIER, 1944, p. 120-121), como uma moradia, por exemplo.

\section{Considerações Finais}

A partir das experiências do sujeito-autor-espiritual da obra temos uma descrição com riqueza de detalhes da cidade/colônia espiritual intitulada de Nosso Lar.

Através das percepções do sujeito-autor-espiritual a obra levanta diversas questões dentre as quais podemos destacar: o sentido do trabalho justo e dignificante; rotina diária; a Lei de causa e efeito a que todos estamos submetidos; de que a vida além da vida tem aspectos muito similares ao da realidade corpórea, ou seja, uma cópia melhorada da nossa realidade ou, invertendo as ideias, a nossa realidade seria uma cópia imperfeita desse plano espiritual; a organização social dessa vida no mundo espiritual. Governadoria, ministérios, transporte coletivo, moradia, salário, tudo isso faz parte da realidade pós morte.

Em consonância com os princípios doutrinários do espiritismo de uma vida além da vida, de um mundo espiritual formado por uma diversidade de espíritos que mais não são do que o espírito daqueles que viveram no plano terreno, Nosso Lar apresenta uma vida no além em grande parte semelhante aquela da vida terrena, com leis, posições sociais, toda

\footnotetext{
10 Por ocasião da Segunda Grande Guerra e, de acordo com o autor espiritual, um amplo trabalho de assistência espiritual e humanitária foi desenvolvido pela colônia Nosso Lar de ajuda à humanidade. O próprio Governador da colônia fez uma longa exortação aos habitantes da colônia expondo a delicadeza do momento e como deveria ser realizado o trabalho de auxílio. "Sua exposição esclarecia que as nações agressoras transformaram-se em núcleos de centralização do mal, influenciados por entidades perversas que se afinavam com os objetivos propostos. Assegurava que falanges de bons Espíritos trabalhavam intensamente, movimentando recursos de auxílio aos agredidos e tentando iluminar as consciências e os corações agressores" (PRATA, 2016, p. 199).
} 
uma vida social que se desenrola no além túmulo que comporta uma estrutura política hierárquica de caráter eminentemente moral, evolutivo e espiritual.

\section{Referências}

ASSIS, Wagner de. Nosso Lar. [Filme]. Produção Cinética Filmes. Coprodução: Migdal Filmes; Globo Filmes. Distribuição Fox Filme do Brasil. Roteiro e Direção Wagner de Assis. Produção executiva Luiz Augusto de Queiroz; Elisabeth Marinho Dias; Wagner de Assis, 2010. 1 DVD. (102 min.).

BERENGUEL, Rosely. Cidade Espiritual Nosso Lar: outras moradas e as câmaras de desnicotinização. Pelo Espírito Adriano Canela M. de Sá. São Paulo: Editora Zennex, 2010. CUNHA, Heigorina. Imagens do Além. Pelo Espírito Lucius. 7. ed. Araras, SP: Instituto de Difusão Espírita, 2009.

CUNHA, Heigorina; XAVIER, Francisco Cândido. Cidade do Além. Pelos Espíritos Lucius e André Luiz. Araras, Sp: Instituto de Difusão Espírita, 1999.

ELIAS, Ana Cecília Moreira. Experiências de Tempo no Umbral: Tempo Subjetivo e Representações do espiritismo através de análises do filme "Nosso Lar". XXVII Simpósio Nacional de História - ANPUH, Natal-RN, 22 a 26 de julho de 2013.

GONÇALVES, Iracilda C. de Freitas. Na discursivização de Nosso Lar: as verdades do Espiritismo. 2011. Tese (Doutorado em Letas). Programa de Pós-Graduação em Letras, Universidade Federal da Paraíba, João Pessoa, 2011.

KÖCHE, José Carlos. Fundamentos de Metodologia Científica: teoria da ciência e iniciação à pesquisa. 34. ed. Petrópolis, RJ: Vozes, 2015.

LEWGOY, Bernardo. A Antropologia Pós-Moderna e a Produção Literária Espírita. Horizontes Antropológicos, Porto Alegre, ano 4, n. 8, p. 87-113, jun. 1998. Disponível em: <http://dx.doi.org/10.1590/S0104-71831998000100006>. Acesso em 06/08/2018.

. Chico Xavier e a Cultura Brasileira. Revista de Antropologia, São Paulo, USP, v.

44, n. 1, p. 51-116, 2001. Disponível em: <http://dx.doi.org/10.1590/S003477012001000100003>. Acesso em 20/07/2018.

PRATA, Denise Adélia V. De Allan Kardec à Chico Xavier: uma visão histórica das poesias e dos romances mediúnicos. 2016. Tese (Doutorado em Letras). Programa de PósGraduação em Estudos Literários, Universidade Federal de Juiz de Fora, Juiz de Fora-MG, 2016.

ROCHA, Alexandre Caroli. O caso Humberto de Campos: autoria literária e mediunidade. 2008. Tese (Doutorado). Programa de Pós-Graduação em Teoria e História Literária. Universidade Estadual de Campinas. Campinas, 2008.

SOARES, Ana Lorym. Um estudo da psicografia como prática letrada, a partir da coleção 'A Vida no Mundo Espiritual' (1944-1968). Revista Expedições: Teoria da História e Historiografia, v. 3, n. 2, p. 130-142, jul./dez., 2012. Disponível em: <http://www.revista.ueg.br/index.php/revista_geth/article/view/1217>. Acesso em 06/08/2018.

STOLL, Sandra Jacqueline. Dos mortos e sua volta: biografia e família na literatura espírita. Debates do NER, Porto Alegre, ano 10, n. 15, p. 151-174, jan./jun., 2009. Disponível em: <http://seer.ufrgs.br/index.php/debatesdoner/article/view/8142>. Acesso em 07/08/2018.

Espiritismo à brasileira. São Paulo: Editora da Universidade de São Paulo. Curitiba: Editora Orion, 2003. 
Narrativas biográficas: a construção da identidade espírita no Brasil e sua fragmentação. Estudos Avançados, vol. 18, n. 52, p. 181-199, set./dez., 2004. Disponível em: <http://dx.doi.org/10.1590/S0103-40142004000300013>. Acesso em 07/07/2018.

VIDAL, Fabiano Cesar de M. Em torno do Nosso Lar: uma análise das controvérsias produzidas no movimento espírita. 2014. Dissertação (Mestrado em Ciências da Religião). Programa de Pós-Graduação em Ciências da Religião. Universidade Federal da Paraíba. João Pessoa, 2014.

XAVIER, Francisco Cândido. Nosso Lar. Pelo Espírito André Luiz. Rio de Janeiro: FEB, 1944. 